\title{
Coping support as rated by back surgery patients
}

\author{
Päivi K. Leikkola ${ }^{* 1,2}$, Mika T. Helminen ${ }^{1,3}$, Eija E-M. Paavilainen ${ }^{1,2}$, Päivi M. Åstedt-Kurki ${ }^{1,3}$ \\ ${ }^{1}$ School of Health Sciences, University of Tampere, Finland \\ ${ }^{2}$ Hospital District of South Ostrobothnia, Seinäjoki, Finland \\ ${ }^{3}$ Hospital District of Pirkanmaa, Department of Research Administration, Tampere, Finland
}

Received: May 26, 2014

DOI: $10.5430 /$ cns.v3n1p62
Accepted: October 26, $2014 \quad$ Online Published: November 28, 2014

URL: http://dx.doi.org/10.5430/cns.v3n1p62

\begin{abstract}
Object: Shorter hospital care periods have brought on new challenges for hospital staff caring for patients and families. New research knowledge of supporting patients and their family members can help to develop their care. This quantitative, descriptive study addresses external coping support to back surgery patients and families and associated factors as rated by them six weeks postoperatively.

Methods: Data were collected from 61 patients and 50 family members in Finland in 2008-2010. The importance of various support forms was measured by a new instrument and overall postoperative coping assessed using the Visual Analog Scale.

Results: For both patients and families, the patient's unchanged behaviour and stable intra-familial emotions, together with the patient education atmosphere were the most important support forms. Patients appreciated staff presence and attention given to self-care motivation, whereas family members felt that hospital staff had not adequately expressed presence or attended to patient education needs. Participants who had experienced stable patient behaviour and intra-familial emotions, rated their overall coping higher 6 weeks postoperatively.
\end{abstract}

Conclusion: Education and staff support affect coping even after some time has elapsed since surgery.

Key Words: Coping, Family, Surgical patient

\section{Introduction}

This paper deals with external coping support provided for back surgery patients and their family members. In the background of the study lies the fact that the number of hospital days per surgery patient has decreased over the years. After discharge, patients are expected to promptly assume responsibility for their own care at home. ${ }^{[1,2]}$ At the same time, the role of family members has grown and mutual support between family members gained in importance. ${ }^{[3]}$ Hospital staff are confronted with the question of how to provide adequate support within a limited time to facilitate both pa- tients' and families coping and self-care. ${ }^{[2,4]}$ Both surgery patients and their families have been found to experience the illness, hospital stay and surgical treatment as stressful. ${ }^{[5,6]}$ The transition from hospital to home is also often marked by feelings of insecurity, stress and coping difficulty and by an increased need for individualized patient education, ${ }^{[2,7]}$ including written self-care instructions and follow-up after discharge. ${ }^{[1,8]}$

Patients and families encountering stressful situations of this kind have been found to require and receive three kinds of social support: informative, emotional and concrete sup-

\footnotetext{
*Correspondence: Päivi K. Leikkola; Email: paivi.leikkola@epshp.fi; Address: Päivi Leikkola, The Hospital District of South Ostrobothnia, FIN-60220 Seinäjoki, Finland.
} 
port. ${ }^{[9]}$ Research has repeatedly confirmed the importance of social support from other people to the whole family recovering from a patient's illness ${ }^{[10,11]}$ seeking and receiving social support is considered to be one of the most crucial external resources during the coping process. ${ }^{[12]}$ As only little research exists on supporting the coping of back surgical patients and their families, much of the literature referred to below deals with other groups of surgical patients. It seems that of the three forms of social support, more research exists on the need and provision of informative and concrete support for surgical patients than on emotional support. The research findings on informative support primarily focus on patient education or counselling provided by nursing staff during the patient's stay in hospital. The burden of concrete support, on the other hand, mostly falls on families after the patient's discharge from hospital. ${ }^{[9,13]}$

Studies that bring clarity to informative support stress the importance of taking into consideration both patients' and their families' education needs. Patients usually wish for their family members to be present in the patient education situation and their needs have been found to vary to one individual to another. ${ }^{[2]}$ Men and women seem to have different needs for patient education and support. ${ }^{[9,14]}$ A study confirmed that female patients required more postoperative education and support. These needs were strongest at the early stage of recovery, when the role of hospital staff was strong. ${ }^{[9]}$ Evidence on how information from hospital staff can promote patients' independence and coping was provided by a study, which revealed how the amount of preoperative information affected recovery in a number of positive ways. Patients became mobile earlier, required less pain medication and followed their rehabilitation programme more actively. They were discharged earlier and suffered fewer postoperative complications. ${ }^{[15]}$ Furthermore, information affected their mental health positively; the patients also reported better psychological coping with surgery. They were more energetic, with lower incidence of anxiety and depression. ${ }^{[16]}$ Another study revealed that inadequate pre-operative patient education increased short stay surgery patients' non-routine visits to health care centres after their discharge from hospital. In conclusion, shortcomings in patient education exercise a negative effect on pain management and postoperative patient satisfaction. ${ }^{[17]}$ General agreement seems to prevail among investigators on the need to provide information on care and hospital operations that is meaningful and adapted to the needs of patients, so that they can make an effort to cope with factors that affect their health. ${ }^{[4,18]}$ Supporting coping and self-care has thus become an essential goal of patient education. ${ }^{[2]}$

Besides patients, informative support is equally important for family members, ${ }^{[11]}$ who have repeatedly been reported to experience the informative support from hospital staff as lacking. ${ }^{[7]}$ According to studies, family members expect support and counselling from hospital staff in order to be able to better assist and support patients. ${ }^{[3,9,19,20]}$ Both patients and their families appreciate information on the patient's pharmacological care. ${ }^{[19]}$ In addition, family members expect to be informed of the patient's status, illness and potential denial of illness. ${ }^{[19,21]}$ They also require information concerning the family's future and expect understanding for the problems that result from the patient's illness. ${ }^{[21]}$ In short, high quality patient education must meet both patients' and their family members' information needs and expectations ${ }^{[19,22]}$ to help them discover their resources and potential and to make them feel in control over their situation during the patient's recovery. ${ }^{[19]}$

Besides the factual information, the way staff approach families is of importance. ${ }^{[23]}$ Emotional support from hospital staff can help patients deal with their fears and promotes their coping and feeling of safety, ${ }^{[6,24]}$ but less research exists on this aspect of support, compared to informative support provided for surgery patients. It has been proposed that in practical terms, hospital staff can encourage and support patients' participation in care by approaching patients as equal partners, by maintaining active interaction and contact with them and by expressing closeness. ${ }^{[25]}$ A study conducted with hand surgical patients suggests that learning to observe the coping strategies used by patients to deal with emotional distress can help staff identify those patients that especially need support. ${ }^{[26]}$ Another study involving patients with degenerative spine disease reveals that patients who experience more social support and less life stress report higher post-surgical quality of life and are more satisfied with the medical outcome of surgery. ${ }^{[27]}$ Similar to patients, family members expect help in understanding their own emotions during the patient's illness. ${ }^{[3]}$ Investigators claim that attending to family members' needs in family nursing can reduce their anxiety, ${ }^{[2,28]}$ increase the family's trust in health services and help achieve better care outcomes. ${ }^{[2]}$ As with patients, sound interaction competence, including efforts to maintain contact, is required from staff, who come to contact with families. ${ }^{[23,29-31]}$ From the patient's viewpoint, the patient's family is an essential source of emotional support. All in all, the family is a crucial resource during rehabilitation, ${ }^{[20]}$ with mutual support promoting all family members' coping, ${ }^{[32]}$ although it must be added that a family member's role may also be to deplete the patient's resources. ${ }^{[3]}$ Support from family members has especially been found to facilitate adaptation to illness. Women as family members have been reported to provide more support than men. ${ }^{[33]}$ Patients, who feel that they have been psychologically supported by their family members during the recovery process are more included to adopt a positive attitude to their recovery and report better experienced health. ${ }^{[9,34]}$

The third kind of social support, concrete support, is usually provided by family members, ${ }^{[13]}$ when patients, after their discharge from hospital, require help in coping with their 
daily activities. Besides concrete assistance the help may involve encouraging and supporting patients in their efforts to attend to various duties. ${ }^{[9]}$ Hospital staff can also undertake concrete supportive action, for example by involving family members in patient care or by facilitating their coming together with other providers of professional care. ${ }^{[11]}$

It would seem, then, on the basis of existing research knowledge that appropriate staff action can promote patient recovery in a number of ways, both during hospital care and after discharge. Patients can more easily find access to their resources and self-care abilities, even at a late stage of their recovery, if they receive adequate information of their condition and its treatment. ${ }^{[19]}$ Involving patients in their own care throughout the recovery period has also been found to be essential, as it increases self-care motivation and satisfaction with care. ${ }^{[25]}$ Careful planning of the overall care, including patient education, can significantly affect postoperative patient satisfaction. Finally, attention given to family members' needs is associated with improved patient care outcomes. ${ }^{[14]}$

\section{Research purpose and questions}

To complement the limited body of knowledge on the topic of support to surgery patients, this study aims at describing various forms of external support provided for post-surgical back patients and their families, including related factors, as rated by them 6 weeks following the operation. The term external support is used to refer to informative, emotional and concrete support provided by hospital staff for patients and their family members during the patient's hospital care. The point of time, 6 weeks post-operatively, was chosen because up until now, little is known of what factors are related to patients' and family members' experiences of external support at a later stage of the patient's recovery. Earlier studies have mostly concentrated on the hospital period and on patients' and families' education needs, but information about the later stage of recovery is required for the development of nursing practice.

The research questions were as follows:

(1) What kind of external support did patients and their family members receive in hospital as rated by them at six weeks following surgery?

(2) Which background factors were associated with the external support received by patients and family members at 6 weeks following surgery?

(3) In what way were the external support received by patients and family members and their overall coping associated at 6 weeks following surgery?

The findings may be useful in the care of patients and their significant others who, as a result of shorter hospitalization periods, need support to cope with new challenges during the patient's recovery. The study provides detailed informa- tion of how patients and family members rate the support and factors associated with it after some time has elapsed since the surgery. This information can be applied in the development of family nursing.

\section{Methods}

\subsection{Design and sample}

A quantitative, descriptive design was employed for this study. Data were collected in the years 2008-2010 in two surgical wards of a central hospital in Finland. Participants were patients and their significant others as defined by patients themselves, also referred to as family members in this research. All patients were adults, who had been surgically treated for disc herniation or spinal stenosis six weeks prior to data collection. There were 61 patients and 50 family members. The inclusion criteria for participants, both patients and family members, included: age 18 or older, Finnish speaking, aware of the study objectives and capable of responding to the questionnaire.

\subsection{Data collection process}

The investigator sent questionnaires along with return envelopes to 126 patients and 126 family members, who met the inclusion criteria. The response rate was $48 \%$ for patients (61 respondents) and $40 \%$ for family members (50 respondents). A long data collection period was required, because many patients and family members declined participation.

All respondents were first presented with 14 questions covering their age, sex, marital status, family and work situation, interests and illness. These were the background factors referred to in the study question number 2 . Second, the instrument contained a section constructed on the basis of earlier research findings and a pilot study, ${ }^{[35]}$ named patients' and family members' coping. This section, which was mainly representative of informative and emotional support provided by staff, contained six literaturebased constructs, each comprising 2-10 structured questions. The constructs were: (1) motivating to self-care; (2) inadequate information; (3) expressing presence; (4) atmosphere in the patient education situation; (5) attending to patient's/family's education needs; (6) patient's behaviour and intra-familial emotions.

Respondents were asked about the importance of the various forms of support for their coping. The questions were four-scale Likert statements (strongly agree, agree, disagree, strongly disagree). ${ }^{[36]}$ The patient's instrument had 38 and the family member's instrument 32 statements and an effort was made to ensure the consistency of the two components, designed for patients and family members respectively. The construct named motivating to self-care contained statements that dealt with receiving knowledge 
from nurses, physiotherapists and doctors on the patient's care and rehabilitation. The construct inadequate information involved questions on the adequacy, clarity and timeliness of oral and written home care instructions. Expressing presence consisted on questions on the hospital staff's (nurses', physiotherapists' and doctors') activity in discussion, their spontaneous offers for help and their efforts to reserve adequate time for the patient and family member. The construct called atmosphere in the patient education situation explored patients' and family members' experiences of safety and professional practice in the patient education situation. The construct attending to patient's/family's education needs measured whether comprehensible and useful information had been provided on the patient's care. Finally, the construct called patient's behaviour and intra-familial emotions contained questions on changed patient behaviour, on the participants' experiences of shame, bitterness and insecurity as a result of the patient's illness, on their discontent with life and their ability to live one day at a time.

Finally, both patients' and family members' instruments contained a Visual Analog Scale (VAS), which respondents used to assess their overall postoperative coping. In earlier studies, VAS has been to used to measure subjective experiences, for example pain, mood, quality of sleep, ability to function and attitudes to environmental factors. In this study, participants were asked to mark their assessment freely on an unmarked scale, after which their scores were determined based on the distance between the left end marker and the participant's mark. The scale had a value range of $0-100$, with 0 points indicating poor and 100 points excellent coping. ${ }^{[37,38]}$

\subsection{Statistical analysis}

For the analysis, responses to items on external support were scored as follows: strongly disagree (1 point), disagree (2 points), agree ( 3 points) and strongly agree ( 4 points). The mean was only calculated when a participant had responded to at least $80 \%$ of the items within a construct. Responses scored at 1 or 2 points represent a minor or negative role of a construct as part of external support, whereas scores of 3 or 4 reflect a more important or positive role. Where needed, items concerning external support were reversed to make the values directionally consistent for analysis. ${ }^{[39]}$ The items within the construct "patient's behaviour and intra-familial emotions" were negatively worded and they dealt with participants' inability to live one day at the time and with their potential bitterness, shame and discontent experienced as a result of the patient's illness. For this construct, low values indicate no change in patient's behaviour or in intra-familial emotions (stability), whereas high values stand for a negative change.

The Statistical Package for the Social Sciences (SPSS) 18.0 was used for analysis. Of the background information, age, sex, marital status and details concerning employment and family are included in the following description. To facilitate data description, one of the background factors, age, was divided into two categories $(<45$ and $\geq 45)$. The results are presented using frequencies, percentages, range, means and medians. The data were not normally distributed, so non-parametric statistical methods (Mann-Whitney and Kruskal-Wallis Test) were used to study the association between background factors and means of constructs. ${ }^{[39]} \mathrm{Be}-$ cause of the limited sample size, any missing information could not be complemented or replaced during the analysis. Spearman's correlation was used to study the relationships between means of constructs and respondents' assessment of their overall postoperative coping. A correlation was determined to be statistically significant if the $p$-value was below .05 .

\subsection{Validity and reliability}

Both patient and family member questionnaires were assessed for reliability and internal consistency of the constructs. The internal consistency of the instruments was found relatively good. ${ }^{[40]}$ Cronbach alpha values were calculated for each construct to assess reliability (see Table 1). As shown in Table 1, in the patient's instrument, the Cronbach alpha values for external support constructs varied between .58 and .87 and in the family member's instrument between .58 and .89 . In testing reliability, the parallelforms method could not be used as no suitable alternative instrument was available. A test-retest analysis was ruled out because the phenomena to be examined were not expected to remain stable over time. ${ }^{[41]}$ Feedback from an expert panel was used to amend and develop the instrument. The panel was also requested to evaluate the face validity of the instruments; using a dichotomous yes-no scale and verbal evaluation, they estimated the degree to which the instruments were suitable for measuring the postoperative coping of back surgery patients and family members. The content validity index calculated on the basis of the evaluation was good for both instruments. ${ }^{[42]}$

National statistics were accessed to learn the total number of target group patients in Finland and to determine an adequate sample size. Based on consultation with a statistician, it was decided that two years would be required to collect adequate data. The investigator made an effort to improve the response rate by a motivating cover letter, an easy-to answer questionnaire and pre-paid envelopes. ${ }^{[43]}$ Since the data collection period was already relatively long, at two years the investigators decided against a repeat enquiry. The respondents would have been past the six week point after surgery, which would have meant investigating another phenomenon. Even six weeks postoperatively may have been too late for some patients and family members to arouse their interest. ${ }^{[41]}$ No power analysis was conducted. Selection bias may have occurred; patients and family members, who had experienced greater postoperative changes 
in their coping, may have been more motivated to respond thermore, patient-family member communication may have than those with less experienced changes in coping. Fur- influenced the responses.

Table 1: Cronbach alpha values for the instrument external coping of patients and family members

\begin{tabular}{lccccc}
\hline \multirow{2}{*}{ Forms of external support for coping } & \multicolumn{2}{c}{ Number of questions } & & \multicolumn{2}{c}{ Cronbach alpha } \\
\cline { 2 - 3 } \cline { 5 - 6 } Motivating for self-care & Patient & Family member & & Patient & Family member \\
\hline Inadequate information & 10 & 8 & 6 & .865 & .891 \\
Expressing presence & 7 & 5 & .798 & .826 \\
Atmosphere of the patient education situation & 9 & 2 & .865 & .895 \\
Attending to patient's/family member's patient & 3 & 3 & .805 & .575 \\
education needs & 7 & & & .578 \\
Patient's behaviour and intra-familial emotions & 38 & 32 & & .830 \\
Total & & & & .585 \\
\hline
\end{tabular}

Even though the modest number of respondents limits the generalizability of the findings, the results can be appreciated, considering how little national and international research knowledge exists on supporting the coping of back surgery patients and their families at a later stage of recovery. The response rate can be considered moderate for a postal questionnaire.

\subsection{Ethical considerations}

The study was conducted in accordance with the ethical principles of the Helsinki Declaration by the World Medical Association. ${ }^{[4]}$ The most important ethical principles relating to this study concern patients' and their family members' informed consent, confidentiality of the information and protection of respondents' privacy. Relevant ethical committee permission (R07165H) and hospital permission were obtained to conduct research. Written informed consent to participate was obtained from all respondents, based on their understanding of the purpose of the study and of the voluntary nature of participation. Questionnaires and consent forms were returned to the investigator by post within one week from receiving them. The results have been reported on as honestly as possible, to the investigator's best understanding. ${ }^{[40]}$

\section{Results}

\subsection{Background information for patients and family members}

As shown in Table 2, patients' mean age was 47.7 years (range 18-71, $n=61$ ). Approximately half of the patients were women. Family members, $54 \%$ of whom were female, had a mean age of 47 (range $18-77, n=50$ ). Most respondents, $77 \%$ of patients and $86 \%$ of family members, were married or co-habiting and the majority of both patients and family members, 70 and $80 \%$ respectively, were working. Most of them had a family with one or more children.

\subsection{Important sources of external support and as- sociated factors}

Table 3 shows that for patients, the atmosphere of the patient education situation and unchanged or stable intra-familial emotions were the most important sources of support for coping. Attention given to patients' self-care motivation and staff's expressions of being present were also found to be supportive of coping.

Similarly, patient education atmosphere was the single most important source of external support for family members, together with the unchanged situation regarding patient behaviour and intra-familial emotions. Family members rated the home care instructions and oral and written information from medical staff as adequate. The hospital staff's expressions of presence, however, had little effect on their coping during the patient's recovery at home; neither did attention given to patients' education needs have any great significance at this stage.

Patients' surgical history was not found to be significantly associated with their rating of their behaviour or intrafamilial emotions as a source of support. The median for patients, who had had surgical treatment for their back problem earlier, was 1.86 , whereas it was 1.36 for the first-timers $(p=.045)$.

In contrast, statistically significant differences were observed between family members who were working and those who were on earnings-related or disability pension. Pensioned family members found staff efforts to motivate patients for self-care insignificant $(\mathrm{m}=1.00)$, whereas working family members had a higher median of 1.75 ( $p$ $=.008)$. Similarly, patient education atmosphere was not an important source of support for pensioned family members at this stage of the patient's recovery; they had a median of 1.00 , while their working peers had a median of $2.50(p=$ $.031)$. In both groups, ratings were low for attention given to patients' and families' education needs; the median for 
pensioned family members' was 1.00 and that for working family members $2.00(p=.007)$.

A special finding in this study was that, similar to patients, unemployed family members also found that they had received adequate information, which supported their coping even at 6 week after the patient's surgery. For unemployed family members the median was 2.83 , but working family members judged the information given as less adequate (median 2.00, $p=.031$ ). Both groups shared the experience that staff had expressed little presence, with medians of 1.00 for unemployed family members and 1.60 for those in working life $(p=.031)$. Staff's expressions of presence did not represent an important source of external support for family members.

Table 2: Patient and family member background data

\begin{tabular}{|c|c|c|c|c|}
\hline \multirow{2}{*}{ Background factors } & \multicolumn{2}{|c|}{ Patient $(\mathrm{N}=61)$} & \multicolumn{2}{|c|}{ Family member $(\mathrm{N}=50)$} \\
\hline & $\mathbf{n}$ & $\%$ & $\mathbf{n}$ & $\%$ \\
\hline \multicolumn{5}{|l|}{ Sex } \\
\hline female & 31 & 51 & 27 & 54 \\
\hline male & 30 & 49 & 23 & 46 \\
\hline \multicolumn{4}{|l|}{ Marital status } & 6 \\
\hline married/co-habiting & 47 & 77 & 43 & 86 \\
\hline divorced & 7 & 11 & 3 & 6 \\
\hline widowed & 1 & 2 & 1 & 2 \\
\hline \multicolumn{5}{|l|}{ On earnings-related/disability pension } \\
\hline no & 43 & 70 & 40 & 80 \\
\hline yes & 15 & 25 & 6 & 12 \\
\hline application pending & 1 & 2 & 1 & 2 \\
\hline \multicolumn{5}{|l|}{ Unemployed } \\
\hline no & 49 & 80 & 44 & 88 \\
\hline yes & 5 & 8 & 3 & 6 \\
\hline \multicolumn{5}{|l|}{ Family members } \\
\hline no children & 11 & 18 & 9 & 18 \\
\hline one or more children & 24 & 39 & 22 & 44 \\
\hline children not living in the same home & 23 & 38 & 14 & 28 \\
\hline
\end{tabular}

A correlation study was conducted to examine the relationship between patients' and family members' overall coping and their assessments of the various forms of external support. As Table 4 shows, the results were found to be similar for patients and family members: All constructs and participants' overall coping were found to have a positive association. The association was especially strong between overall coping and the construct for patient behaviour and intra-familial emotions. Those patients and family members, who had not experienced negative changes in the patient's behaviour and in intra-familial emotions, rated their overall coping more positively at six weeks after the surgery.

\section{Discussion}

The results confirm the importance of support provision in the care of patients and their families, even as rated at a later stage of the patient's recovery process. In this study, the most important forms of external support for patients' coping, as reported by them six weeks after discharge, were related to the patient education atmosphere, supported by stable patient behaviour and intra-familial emotions. The patients also regarded the activity of the hospital staff, especially staff's expressions of being present and their efforts to motivate patients to self-care, as positive sources of support for coping. Furthermore, the patients, whose own behaviour and intra-familial emotions had remained stable, rated their overall coping higher.

The results are consistent with earlier findings on the crucial role of hospital staff in promoting postoperative patient independence and coping. ${ }^{[1,2]}$ Adequate information provision, which has been found to affect patients' physical and psychological wellbeing positively, ${ }^{[15,16]}$ was rated among important sources of external support for patients' coping at six weeks after the surgery. No differences were observed between the ratings by men and women. ${ }^{[9,14]}$

Also for the family members in this study, stable patient behaviour and intra-familial emotions, together with the patient education atmosphere, were the most important sources of support for their coping. All family members found that they had received adequate oral and written information. However, staff efforts to motivate patients for self-care had had little effect on the coping of pensioned 
family members, according to family members' report at six weeks after the patient's surgery. Pensioned family members also rated the attention given to their education needs as insufficient. Similar to patients, all family members felt that their overall coping was better at 6 weeks postoperatively, because there had been no negative changes in patient behaviour and intra-familial emotions.

Table 3: Patients' and family members' assessment of the importance of external support for coping

\begin{tabular}{lccccc}
\hline \multirow{2}{*}{ Forms of external support for coping } & \multicolumn{2}{c}{ Median (n) } & & \multicolumn{2}{c}{$\mathbf{Q}=\mathbf{Q 1 - Q 3}$} \\
\cline { 2 - 3 } \cline { 5 - 6 } & Patient & Family member & & Patient & Family member \\
\hline Motivating to self-care & $3.20(61)$ & $1.75(48)$ & & $2.80-3.65$ & $1.41-2.47$ \\
Inadequate information & $2.71(58)$ & $2.17(46)$ & & $2.00-3.14$ & $1.50-2.83$ \\
Expressing presence & $3.11(61)$ & $1.60(46)$ & & $2.67-3.67$ & $1.00-2.40$ \\
$\begin{array}{l}\text { Atmosphere of the patient education situation } \\
\text { Attending to patient's/family member's }\end{array}$ & $3.50(60)$ & $2.50(41)$ & & $3.00-4.00$ & $1.50-3.00$ \\
$\begin{array}{l}\text { education needs } \\
\begin{array}{l}\text { Patient's behaviour and intra-familial } \\
\text { emotions }\end{array}\end{array}$ & $3.00(59)$ & $2.00(42)$ & & $2.67-3.33$ & $1.33-2.67$ \\
\hline
\end{tabular}

Scale 1-4: 4 = strongly agree, 3 = agree, 2 = disagree, 1 = strongly disagree; *Reverse ordering with low values indicating positive meaning.

The findings are in accordance with other studies which stress the importance of interaction and adequate information from hospital staff in supporting families' coping. ${ }^{[3,9,21,23]}$ This study confirms that the support partly remains effective even later, during the patient's recovery at home. Unfortunately, this was not true of pensioned family members, whose expectations were not met and who felt that they had received little support. Other investigators have also found that family members tend to expect more from hospital staff than what they actually receive. ${ }^{[9,19,20,28]}$ As in other studies, ${ }^{[10]}$ support between family members was found to be crucial, even at six week after the patient's surgery. The fact that the patient's behaviour and intra-familial emotions remained stable in the face of illness proved an important source of support. In general, the results highlight the importance of meaningful support in caring for patients and families even after some time has elapsed since the surgery.

Table 4: Correlation study (Spearman's correlation); association between means of constructs and patients' and family members' assessment of their overall coping

\begin{tabular}{|c|c|c|c|c|c|c|}
\hline \multirow{2}{*}{$\begin{array}{l}\text { Forms of external support } \\
\text { for coping }\end{array}$} & \multicolumn{2}{|c|}{ Correlation } & \multicolumn{2}{|c|}{$P$ value } & \multicolumn{2}{|c|}{$\mathbf{N}$} \\
\hline & Patient & $\begin{array}{c}\text { Family } \\
\text { members }\end{array}$ & Patient & $\begin{array}{l}\text { Family } \\
\text { member }\end{array}$ & Patient & $\begin{array}{l}\text { Family } \\
\text { member }\end{array}$ \\
\hline Motivating for self-care & .355 & .074 & .005 & .615 & 61 & 48 \\
\hline Inadequate information & .306 & -.190 & .019 & .207 & 58 & 46 \\
\hline Expressing presence & .154 & .045 & .235 & .767 & 61 & 46 \\
\hline $\begin{array}{l}\text { Atmosphere of the patient } \\
\text { education situation }\end{array}$ & .389 & .245 & .002 & .122 & 60 & 41 \\
\hline $\begin{array}{l}\text { Attending to patient's/family } \\
\text { member's education needs }\end{array}$ & .145 & -.066 & .273 & .680 & 59 & 42 \\
\hline $\begin{array}{l}\text { Patient's behaviour and } \\
\text { intra-familial emotions }\end{array}$ & $-.711^{\#}$ & $-.548^{\#}$ & .000 & .000 & 61 & 49 \\
\hline
\end{tabular}

"Reverse ordering with low values indicating positive meaning; ; Practically significant results (> .4) are indicated in bold.

Different sources of support are important to patients and family members, so their needs should be addressed individually. It is a positive sign if staff can confirm that there are no negative changes in patients' behaviour or in intrafamilial emotions. Further practical development work is indicated to ensure staff competence to meet family members' education needs. Practical models are needed to help staff take into consideration the various forms of external support when they seek to ensure patients' and family members' postoperative coping. The results of patient education given should be visible and effective even later during the recovery process. Patient education could also be brought to people's homes, for example with the help of information technology. 


\section{Conclusion}

The results of this research can make nurses and other hospital staff aware of the fact that their actions during patients' hospital care have considerable significance for supporting the coping of patients and family members. The care, education and support provided during hospitalization have longterm effects, up to and beyond 6 weeks following surgery. Even brief interactive situations with staff can be meaningful to patients and family members.

\section{References}

[1] Leino-Kilpi H, Johansson K, Heikkinen K, et al. Patient education and health-related quality of life: surgical hospital patients as a case in point. J Nurs Care Qual. 2005; 20(4): 307-16. PMid:16177581. http://dx.doi.org/10.1097/00001786-200510000-00005

[2] Kääriäinen M, Kyngäs $H$. Patient counselling in nursing research published during 1995-2002. Hoitotiede. 2005; 17(4): 208-16.

[3] Aura M, Paavilainen E, Asikainen P, et al. Experiences of the family member of an adult patient on the support received from the nursing staff. Tutkiva Hoitotyö. 2010; 8(2): 14-21.

[4] Salanterä S, Virtanen H, Johansson K, et al. Evaluation of written patient education material in university hospital. Hoitotiede. 2005; 17(4): 217-228.

[5] Mayne IP, Bagaoisan C. Social Support During Anesthesia Induction in an Adult Surgical Population. AORN. 2009; 89(2): 307320. PMid:19200465. http://dx.doi.org/10.1016/j.aorn. 2008.09.015

[6] Mattila E, Kaunonen M, Aalto P, et al. Support for hospital patients and associated factors. Scand J Caring Sci. 2010; 24(4): 734745. PMid:20409062. http://dx.doi.org/10.1111/j.1471-6 $712.2010 .00771 . \mathrm{x}$

[7] Boughton M, Halliday L. Home alone: Patient and carer uncertainty surrounding discharge with continuing clinical care needs. Contemp Nurse. 2009; 33(1): 30-40. http://dx.doi.org/10.5172/con u. 33.1 .30

[8] Lam P, White CL, Runions S, et al. Continuity of care for shortstay neurosurgery patients: a quality improvement initiative. Axon. 2001; 23(2): 14-21. PMid:14621497.

[9] Rantanen A. Coronary artery bypass grafting patients' and their significant others' health-related quality of life and social support. English abstract. Academic dissertation, Tampere, Finland: University of Tampere; 2009. 106p.

[10] Kyngäs H. Youth with diabetes and their families. Family in Nursing, Research and Practice. Porvoo, Finland: WSOY; 1999. 307$19 \mathrm{p}$.

[11] Saban KL, Penckofer SM, Androwich I, et al. Health-related quality of life of patients following selected types of lumbar spinal surgery: a pilot study. Health Qual Out. 2007; 5: 71. http://dx.doi.org /10.1186/1477-7525-5-71

[12] Lazarus RS, Folkman S. Stress, appraisal and coping. New York: Springer publishing Co. 1984. 141-80p.

[13] Heino T. Counselling of a day surgery arthroscopy patient in the patient's experience, English abstract. Academic dissertation. University of Tampere; 2005. 130p.

[14] Banner D, Miers M, Clarke B, et al. Women's experiences of undergoing coronary artery bypass graft surgery. J Adv Nurs. 2011; 68(4): 919-30. PMid:21834836. http://dx.doi.org/10.1111/j.136 5-2648.2011.05799.x

[15] Gammon J, Mullholland CW. Effect of preparatory information prior to elective total hip replacement on post-operative physical coping outcomes. Int J Nurs Stud. 1996b; 33(6): 589-604. http: //dx.doi.org/10.1016/S0020-7489(96)00019-3
[16] Gammon J, Mullholland CW. Effect of preparatory information prior to elective total hip replacement on psychological coping outcomes. J Adv Nurs. 1996a; 24: 303-8. PMid:8858434. http://dx .doi.org/10.1046/j.1365-2648.1996.17911.x

[17] McCloud C, Harrington A, King L. Understanding people's experience of vitreo-retinal day surgery: a Gadamerian-guided study. J Adv Nurs. 2011; 68(1): 94-103. PMid:21815913. http://dx.doi $. \mathrm{org} / 10.1111 / \mathrm{j} .1365-2648.2011 .05720 . \mathrm{x}$

[18] Giske T, Gjengedal E. Preparative waiting and coping theory with patients going through gastric diagnosis. J Adv Nurs. 2006; 87-94.

[19] Paavilainen E, Salminen-Tuomaala M, Leikkola P. Counselling for patients and family members: a follow-up study in the emergency department. ISRN Nursing. 2012. http://dx. doi .org/10.5402 $/ 2012 / 303790$

[20] Lipponen K, Kyngäs H, Kääriäinen M. Challenges in patient counselling: counselling models applicable to practical nursing. Publication Series of the Northern Ostrobothnia Hospital Disctrict Oulu 4. Oulu. Finland: Oulu University Press; 2006; 45-6p.

[21] Wideheim AK, Edvardsson T, Påhlson A, et al. A family's perspective on living with a highly malignant brain tumor. Cancer Nurs. 2002; 25(3): 236-44. PMid:12040233. http://dx.doi.org/10. 1097/00002820-200206000-00012

[22] Kääriäinen M, Kyngäs $H$. The quality of patient education evaluated by the health personnel. Scand J Caring Sci. 2010; 24: 54856. PMid:20409053. http://dx.doi.org/10.1111/j.1471-6 712.2009.00747.x

[23] Rantanen A, Heikkilä A, Asikainen P, et al. Support received by families in health care: a pilot study. Hoitotiede. 2010; 22(2): 14152.

[24] Koivula M. Fear, anxiety and social support of coronary artery bypass surgery patients, English abstract. Academic dissertation. Tampere, Finland: University of Tampere; 2002. 123p.

[25] Sahlsten MJM, Larsson IE, Sjöström B, et al. Patient participation in nursing care: towards a concept clarification from a nurse perspective. J Clin Nurs. 2007; 16: 630-37. http://dx.doi.org/1 $0.1111 / j .1365-2702.2006 .01660 . x$

[26] Gustafsson M, Ahlström G. Emotional distress and coping in the early stage of recovery following acute traumatic hand injury: a questionnaire survey. Int J Nurs Stud. 2006; 43(5): 557565. PMid:16150449. http://dx.doi.org/10.1016/j.ijnur stu. 2005.07.006

[27] Laxton AW, Perrin RG. The relations between social support, life stress, and quality of life following spinal decompression surgery. Spinal Cord. 2003; 41(10): 553-558. PMid:14504612. http://dx .doi.org/10.1038/sj.sc.3101432

[28] Cypress B. The intensive care unit: experiences of patients, families and their nurses. Dimens Crit Care Nurs. 2010; 29(2): 94101. PMid:20160552. http://dx.doi.org/10.1097/DCC.0b0 $13 \mathrm{e} 3181 \mathrm{c} 9311 \mathrm{a}$

[29] Jangland E, Larsson J, Gunning berg L. Surgical nurses' different understandings of their interactions with patients: a phenomenographic study. Scand J Caring Sci. 2010; 25: 533-41.

[30] Moore CD, Bernardini GL, Hinerman R, et al. The effect of a family support intervention on physician, nurse, and family perceptions of care in the surgical, neurological, and medical inten- 
sive care units. Crit Care Nurs Q. 2012; 35(4): 378-87. http: //dx.doi.org/10.1097/CNQ.0b013e318268fde3

[31] Perälä M L, Räikkönen O, Hernesniemi P. Co-operation in central hospital evaluated by surgical patients' relatives, English summary. Hoitotiede. 1999; 11(1): 13-21.

[32] Wyness MA, Durity MB, Durity F. Narratives of patients with skull base tumors and their family members: lessons for nursing practice. Axon. 2002; 24(1): 18-35. PMid:12387113.

[33] Luszczynska A, Gerstorf D, Boehmer S, et al. Patients' coping profiles and partners' support provision. Psychol Health. 2007; 22(7): 749-764. http://dx.doi.org/10.1080/14768320600976232

[34] Okkonen E, Vanhanen H. Family support, living alone and subjective health of a patient in connection with coronary artery bypass surgery. Heart Lung. 2006; 35(4): 234-44. PMid:16863895. http://dx.doi.org/10.1016/j.hrtlng.2005.11.002

[35] Leikkola P. Postoperative coping of neurosurgical patients and their family members. Master's Thesis. Tampere, Finland: University of Tampere; 2006. 84p.

[36] Leikkola P, Helminen M, Paavilainen E, et al. Back surgical patients' and their family members' coping resources at discharge from hospital. Tutkiva Hoitotyö. 2013; 11(3): 27-36.
[37] Burns N, Grove SK. Understanding nursing research: building an evidence-based practice. 4th ed. Philadelphia PA: Elsevier Saunders; 2007. 390-91p.

[38] Polit D, Beck C, Hungler B. Essentials of nursing research methods, appraisal and utilization. 5th ed. Philadelphia, PA: Lippincott; 2001. 273p.

[39] Burns N, Grove SK. The practice of nursing research: Conduct, critique \& utilization. 5th ed. MO: Elsevier Saunders; 2005. 441-60p. PMid:15645327.

[40] Burns N, Grove S. Understanding nursing research. 3rd ed. Philadelphia, PA: Saunders; 2003. 259-60p.

[41] Polit D, Beck C. Nursing research: Appraising evidence for nursing practice. 7th ed. Philadelphia, PA: Lippincott; 2010. 413-15p.

[42] Vehviläinen-Julkunen K, Paunonen M. Reliability of quantitative research. Research methodology in nursing science. Porvoo, Finland: WSOY; 2006. 206-14p.

[43] Heikkilä T. Statistical Research. 7th - 8th ed. Helsinki, Finland: Edita Prima oy; 2010. 66-7p.

[44] The World Medical Association. Declaration of Helsinki: ethical principles for medical research involving human subjects [Internet]. 1964 [last revised by the 59th General Assembly in 2008]. Available from: http://www.wma.net/en/30publications/10po licies/b3/ 